Research Article

\title{
Dependence of Adhesion Properties on Blend Ratio of Ethylene-Propylene-Diene Rubber/Standard Malaysian Rubber Blend Adhesive
}

\author{
B. T. Poh, J. Lamaming, and G. S. Tay \\ School of Industrial Technology, Universiti Sains Malaysia, 11800 Penang, Malaysia \\ Correspondence should be addressed to B. T. Poh; btpoh@usm.my
}

Received 15 May 2013; Revised 1 November 2013; Accepted 8 November 2013

Academic Editor: Fahmina Zafar

Copyright (C) 2013 B. T. Poh et al. This is an open access article distributed under the Creative Commons Attribution License, which permits unrestricted use, distribution, and reproduction in any medium, provided the original work is properly cited.

\begin{abstract}
Viscosity, tack and, peel and shear strengths of ethylene-propylene-diene rubber (EPDM)/standard Malaysian rubber (SMR L) blend adhesive were studied using various blend ratios of the two rubbers, ranging from 0 to $100 \%$ EPDM. Coumarone-indene resin, toluene, and poly(ethylene terephthalate) (PET) were used as the tackifier, solvent, and coating substrate, respectively. The tackifier content was fixed at 40 parts per hundred parts of rubber (phr). A SHEEN hand coater was used to coat the adhesive on PET film at four coating thicknesses, that is, 30,60,90, and $120 \mu \mathrm{m}$. The viscosity and adhesion properties were determined by a Brookfield viscometer and a Lloyd Adhesion Tester, respectively. Results show that the viscosity, loop tacks and peel strength of blend adhesives decrease gradually with increasing \% EPDM. This observation is attributed to dilution effect and lowering in wettability and compatibility. Shear strength, however, passes through a maximum at $20-40 \%$ EPDM blend ratio, an observation which is ascribed to culmination of cohesive strength at the optimum EPDM blend ratio. Increasing coating thickness increases the adhesion properties in all blend ratios in this study.
\end{abstract}

\section{Introduction}

Natural rubber is widely used to prepare pressure-sensitive adhesives. However, natural rubber alone has a very low tack and adhesion to surfaces [1]. Hence, it is necessary to add tackifier to the elastomer to produce the required balance of tack, peel adhesion, and resistance to shear forces. In formulating a rubber-based pressure-sensitive adhesive, an elastomer provides the elastic component whereas a low molecular weight tackifier imparts the viscous component. The adhesion properties of natural-rubber-based adhesives have been investigated by several researchers. Leong et al. [2] have studied the viscoelastic properties of natural rubber pressure-sensitive adhesive using acrylic resin as a tackifier. Fujita et al. [3,4] reported the effects of miscibility and viscoelasticity on peel strength and shear creep resistance of natural-rubber-based pressure-sensitive adhesives. However, most of the rubber-based adhesives are prepared using one type of elastomer. Research works on rubber-blend-based adhesives are not widely reported. Phillips et al. $[5,6]$ have studied the nano- and bulk-tack adhesive properties of stimuli-response and fullerene-polymer blends containing polystyrene-block-polybutadiene-block-polystyrene and polystyrene-block-polyisoprene-block-polystyrene rubber-based adhesives. It was found that the presence of oxygen was essential to the mechanism of adhesive loss of the rubber blends. Smitthipong et al. [7] studied the self-adhesion of immiscible polyisoprene rubber-hydrogenated acrylonitrile butadiene rubber blends. They concluded that the selfadhesion energy of the blend increases with contact time. The pressure-sensitive adhesive applications of compatible blend of styrene-vinyl acetate copolymer/natural rubber latex by irradiation and chemical initiation were also reported by Magida et al. [8]. On the other hand, Stephen et al. [9] published the adhesive formulations with ternary blends using simplex lattice design whereas Da Silva et al. [10] and Riyajan and Pheweaw [11] investigated the adhesive performance of synthetic rubber blend and natural rubber blend, respectively. The effect of magnesium methacrylate and zinc methacrylate 
TABLE 1: Dimensions of peel test sample.

\begin{tabular}{lcc}
\hline Mode of peel test & Base stock & Face stock \\
\hline T-peel & $20 \mathrm{~cm} \times 4 \mathrm{~cm}$ & $20 \mathrm{~cm} \times 4 \mathrm{~cm}$ \\
$90^{\circ}$ peel & $20 \mathrm{~cm} \times 4 \mathrm{~cm}$ & $15 \mathrm{~cm} \times 7 \mathrm{~cm}$ \\
$180^{\circ}$ peel & $25 \mathrm{~cm} \times 4 \mathrm{~cm}$ & $10 \mathrm{~cm} \times 10 \mathrm{~cm}$ \\
\hline
\end{tabular}

on bond properties of thermal insulation material based on NBR/EPDM blends was also investigated by Gao et al. [12]. Recently, we have carried out a few studies on the adhesion properties of natural rubber/synthetic rubber blends [13-15]. Results show that adhesion properties strongly depend on the rubber blend ratio where maximum values are observed at certain blend ratio. This finding is associated with the optimum wettability of adhesive on the substrate. SMR L is one grade of natural rubber that consists of unsaturated double bonds along the cis-polyisoprene chains which is exposed to oxidation. The oxidative aging of SMR L has a degrading effect of chain scission resulting in loss of cohesive strength. On the other hand, EPDM is a synthetic rubber well known for its heat and aging resistance because of its saturated bonds along the main chain backbone. Blending of EPDM with SMR L would inevitably enhance its oxidative resistance. This means that the shelf life of EPDM/SMR L products including pressure-sensitive adhesives would be prolonged. Since there is no systematic research conducted on the EPDM/SMR L blend-based adhesive, it is thus the aim of this project to report on our findings of the adhesion properties of adhesive prepared from the novel rubber blend system, that is, EPDM/SMR L blend.

\section{Experiment}

2.1. Materials. Natural rubber (SMR L grade) and ethylenepropylene-diene rubber (EPDM) were used as the elastomers. SMR L and EPDM were supplied by Rubber Research Institute of Malaysia and LANXESS Company, respectively. EPDM has an ethylene and ENB content of $67 \%$ and $4.3 \%$ respectively. Glass transition temperature and Mooney viscosity for SMR L are $-72^{\circ} \mathrm{C}$ and 78 , respectively whereas the corresponding values for EPDM are $-60^{\circ} \mathrm{C}$ and 63 . Coumarone-indene resin, toluene, and PET film were used as the tackifier, solvent, and substrate, respectively throughout the experiment.

2.2. Adhesive Preparation. Both rubbers were masticated using a 2-roll mill for 10 minutes to ensure easy dissolution in solvent. Various EPDM/SMR L blends ratios, that is, $0 / 5,1 / 4$, $2 / 3,3 / 2,4 / 1$, and $5 / 0$ corresponding to $0,20,40,60,80$, and $100 \%$, EPDM were prepared. Each rubber blend was dissolved in $30 \mathrm{~mL}$ of toluene. It was then tightly closed and kept for 24 hours at room temperature $\left(30^{\circ} \mathrm{C}\right)$ to ensure complete dissolution of the rubber blend. A fixed amount of $2 \mathrm{~g}$ of pulverized coumarone-indene resin, which corresponded to 40 phr of resin, was added gently to the rubber solution with constant stirring. The rubber blend adhesives produced were left for 3 hours at room temperature prior to testing.

\section{Measurement}

3.1. Viscosity. A Brookfield viscometer (model DV-II + Pro) was used to determine the viscosity of the rubber blend adhesives at a testing speed of $1 \mathrm{rpm}$. The spindle (CPE-51) and metal cup (CPE-44 Y) were used in the measurement. Prior to testing, the platform and spindle head were cleaned with isopropyl alcohol. A drop of adhesive was then placed at the middle of the platform and measurement was carried out for one minute. The average viscosity was noted from at least five readings.

3.2. Tack. A SHEEN hand coater was used to coat a PET film substrate $(4 \mathrm{~cm} \times 25 \mathrm{~cm})$ at the centre of the substrate $(4 \mathrm{~cm} \times$ $4 \mathrm{~cm}$ ) with different coating thickness. The coated sample was left at room temperature for 24 hours before measurement. A loop was then formed with the coated area outside the loop. It was slowly brought into contact with a clean glass plate without any force other than the pushing force on the loop. The testing was carried out on a Lloyd Adhesion Tester (Model LRXPlus with NEXYGEN software) operating at a testing rate of $30 \mathrm{~cm} / \mathrm{min}$. The average debonding force was calculated from the three highest peaks obtained from the test. Loop tack was expressed as the debonding force per unit area of contact $\left(\mathrm{N} / \mathrm{m}^{2}\right)$.

3.3. Peel Strength. Peel strength was determined by three modes of peel testing, that is, T-peel, $90^{\circ}$-Peel, and $180^{\circ}$-peel tests. The dimensions of the base and face stocks for the respective peel tests are shown in Table 1 .

A SHEEN hand coater was used to coat the adhesive from the end of PET film at a coating area of $10 \mathrm{~cm} \times$ $4 \mathrm{~cm}$ for various coating thicknesses. The face stock was then gently laid on the coated PET film (base stock). The coated specimen was conditioned at room temperature for 24 hours before testing on a Llyod Adhesion Tester operating at $30 \mathrm{~cm} / \mathrm{min}$. The average peeling force was determined from the three highest peaks recorded from the test. Peel strength was defined as the peel force per unit width of substrate.

3.4. Shear Strength. PET film with dimensions of $20 \mathrm{~cm} \times$ $4 \mathrm{~cm}$ was used as the substrate for the shear strength test. The adhesive was coated on a $10 \mathrm{~cm}$ length from the end of the substrate to form the base stock. One end of another uncoated substrate (face stock) was carefully laid on the coated area of the base stock. The testing specimen was then conditioned at room temperature for 24 hours. It was then tested on a Llyod Adhesion Tester operating at $30 \mathrm{~cm} / \mathrm{min}$. Shear strength was expressed as the shear force per unit area of testing.

\section{Results and Discussion}

The effect of \% EPDM on viscosity, tack, peel strength, and shear strength of EPDM/SMR L blend adhesives is systematically discussed as below.

4.1. Viscosity. Figure 1 shows the effect of EPDM content on the viscosity of EPDM/SMR L blend adhesive. From 


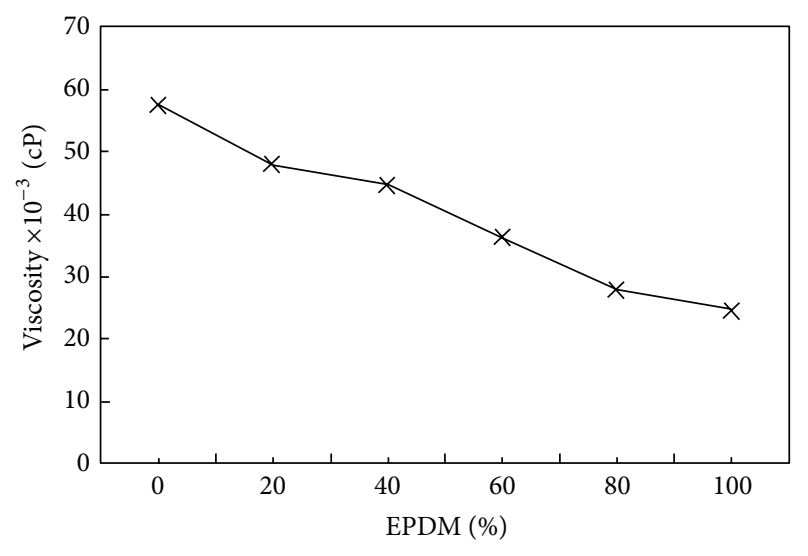

FIGURE 1: Variation of viscosity with \% EPDM for EPDM/SMR L blend adhesive.

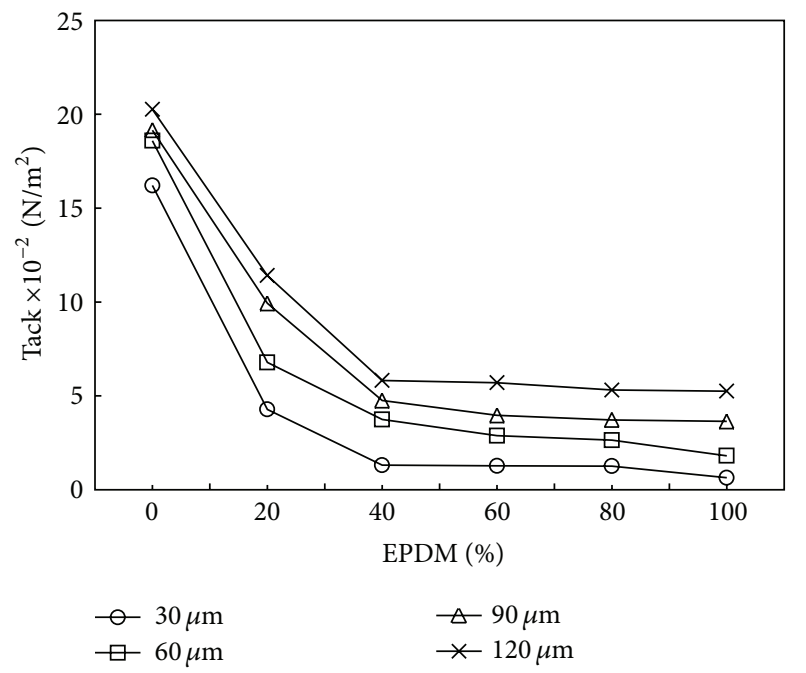

FIGURE 2: Variation of tack with \% EPDM for EPDM/SMR L blend adhesive at various coating thicknesses.

the plot, it indicates that viscosity decreases steadily with increase in \% EPDM content. The highest viscosity is shown by $100 \%$ SMR L and lowest viscosity is exhibited by $100 \%$ EPDM content. The decreasing behaviour in viscosity with increasing EPDM content is attributed to lower Mooney viscosity of EPDM compared to that of SMR L; that is, EPDM has a lower molecular weight than SMR L. Result indicates that the viscosity of SMR L-based adhesive is $57.2 \%$ higher than that of EPDM-based adhesive. The drop in viscosity for the EPDM/SMR L blend adhesive with increase in \% EPDM component is primarily associated with the dilution effect of EPDM due to the lower viscosity of EPDM.

4.2. Tack. Tack may be defined as the property of a material which enables it to form a bond of measurable strength immediately upon contact with another surface with low applied pressure $[1,16]$. The dependence of loop tack on $\%$ EPDM of EPDM/SMR L blend adhesives for various coating thicknesses is shown in Figure 2.

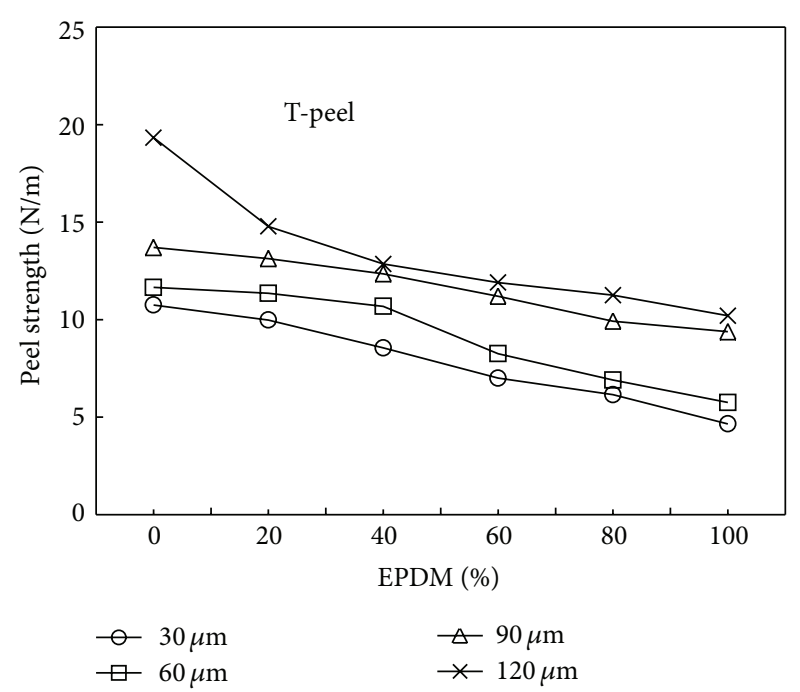

FIGURE 3: Variation of peel strength (T-peel test) with \% EPDM for EPDM/SMR L blend adhesive at various coating thicknesses.

Rapid drop in tack is observed up to $40 \%$ EPDM, after which tack value remains essentially independent of $\%$ EPDM for all coating thicknesses investigated in this study. The initial rapid decrease in tack is attributed to the decrease in wettability of the adhesive due to the nontacky behavior of EPDM. Phase inversion occurs after 40\% EPDM content where the tack behavior is dominated by the presence of EPDM as reflected by the nearly constant tack value after $40 \%$ EPDM content. For a fixed EPDM content, $120 \mu \mathrm{m}$ coated sample consistently exhibits the highest tack value, followed by $90 \mu \mathrm{m}, 60 \mu \mathrm{m}$, and $30 \mu \mathrm{m}$ coated samples. This phenomenon is attributed to the higher amount of adhesive in thicker coated samples which would enhance the viscoelastic response of the rubber blend adhesives. At higher coating thicknesses and high \% EPDM, there is enough amount of adhesive to provide the same viscoelastic response and hence tack shows similar value between 80 and 100\% EPDM samples.

4.3. Peel Strength. The effect of $\%$ EPDM on the peel strength is shown in Figures 3, 4, and 5 for T-peel, $90^{\circ}$ peel, and $180^{\circ}$ peel tests, respectively All the plots indicate that peel strength decreases with increasing \% EPDM. The decrease in peel strength is more significant in the case of $90^{\circ}$ and $180^{\circ}$ peel tests where the respective peel strength drops rapidly from 0 to 20\% EPDM content. Further increase in \% EPDM is accompanied by a gradual decrease in peel strength of the adhesive. This observation is attributed to the decrease in wettability of adhesive as \% EPDM is increased. Hence, mechanical interlocking and anchorage of the adhesive in pores and irregularities in the adherent do not occur. The high content of ethylene (67\%) in EPDM has made the rubber not very rubbery [17]. This nonrubbery behaviour of EPDM has decreased the viscoelastic properties of the rubber blend adhesive and consequently lowers the peel property of EPDM/SMR L blend adhesives as shown in Figures 3, 


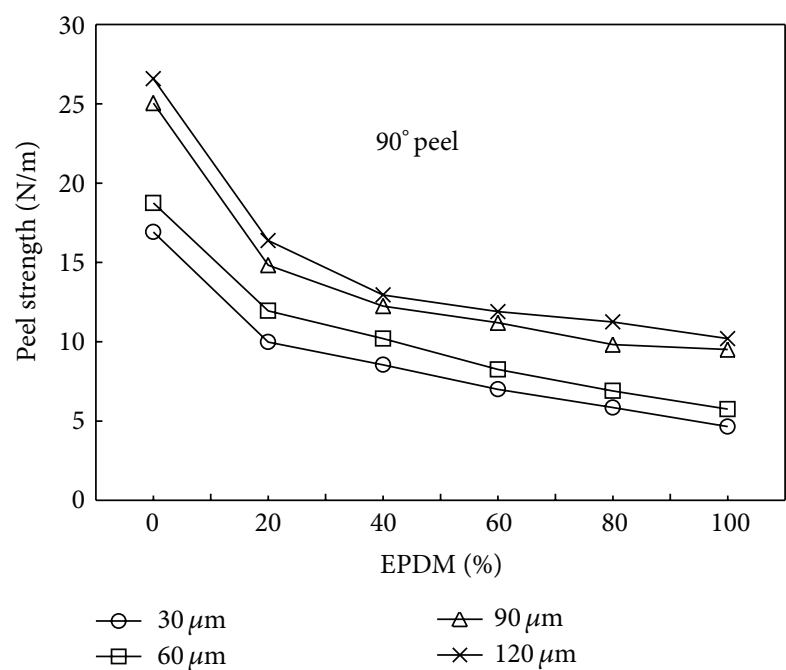

FIGURE 4: Variation of peel strength $\left(90^{\circ}\right.$-peel test) with \% EPDM for EPDM/SMR L blend adhesive at various coating thicknesses.

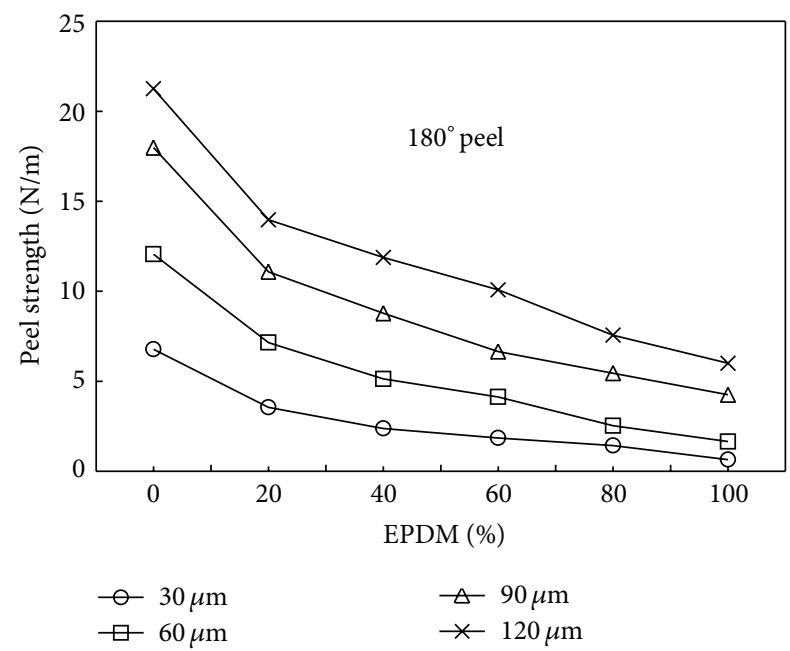

FIGURE 5: Variation of peel strength $\left(180^{\circ}\right.$-peel test $)$ with \% EPDM for EPDM/SMR L blend adhesive at various coating thicknesses.

4, and 5. The properties of pressure-sensitive adhesive are strongly dependent on the viscoelastic property; that is, proper flow and wetting characteristics are essential for a good pressure-sensitive adhesive [2]. For a fixed \% EPDM, the $120 \mu \mathrm{m}$ coated sample consistently exhibits the highest peel strength followed by $90 \mu \mathrm{m}, 60 \mu \mathrm{m}$, and $30 \mu \mathrm{m}$ thicknesses for the three modes of peel tests. This phenomenon is associated with higher amount of adhesive in thicker coated sample. Increasing the adhesive thickness causes the shift from cohesive to adhesive failure where it is associated with the transition from viscous like liquid to rubberlike elastic behaviour [18]. The peel strength of sample coated at $120 \mu \mathrm{m}$ thickness is found to be varying from Figures 3, 4, and 5 because of the angle of peel testing. From the plots at $120 \mu \mathrm{m}$, it is obvious that $90^{\circ}$ peel test gives the highest peel strength. This observation is attributed to the higher peel force needed

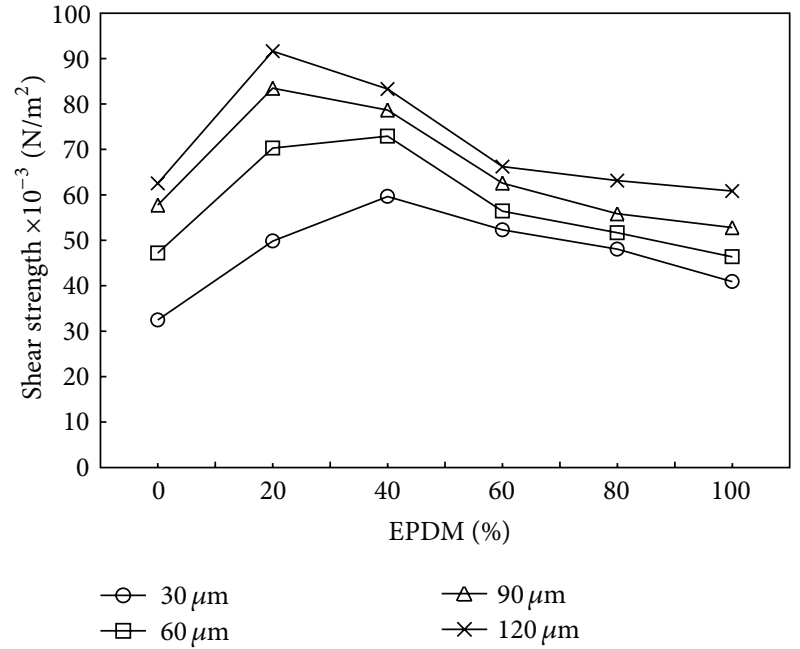

FIGURE 6: Variation of shear strength with \% EPDM for EPDM/SMR $\mathrm{L}$ blend adhesive at various coating thicknesses.

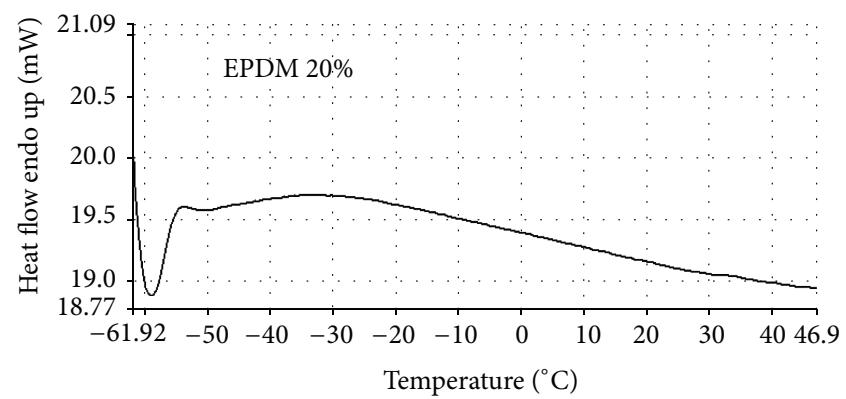

FIGURE 7: A DSC thermograph of EPDM/SMR L blend adhesive containing 20\% EPDM.

in the $90^{\circ}$ peel test where the rubber chains undergo more strain-induced crystallization $[19,20]$.

4.4. Shear Strength. The dependence of shear strength on $\%$ EPDM is shown in Figure 6 for various coating thicknesses. Shear strength passes through a maximum value at $20 \%$ EPDM content for $90 \mu \mathrm{m}$ and $120 \mu \mathrm{m}$ coating thicknesses. For the lower coating thickness, that is, $30 \mu \mathrm{m}$ and $60 \mu \mathrm{m}$, maximum shear strength is observed at higher EPDM content of $40 \%$. Maximum shear strength occurs at lower \% EPDM content for thicker coated sample because of the earlier culmination of cohesive and adhesive strength at the $20 \%$ EPDM content compared to the lower coating thickness. However, after the optimum EPDM content, shear strength decreases with further increase in EPDM content for all coating thicknesses. This observation is due to the drop in adhesive strength with further increase in EPDM content as discussed earlier. For a fixed \% EPDM content, shear strength increases with coating thickness of adhesive. This observation is ascribed to the higher amount of adhesive present in thicker coated sample which increases the cohesive strength and hence enhances the shear resistance of the adhesive. 
Figure 7 shows the Differential Scanning Calorimetric (DSC) thermograph for 20\% EPDM which is the optimum blend ratio. Compatibility and miscibility between the rubber blend and the tackifier system are confirmed by a single glass transition as indicated by the thermograph. This compatibility enhances the adhesion property of EPDM/SMR L blend adhesives.

\section{Conclusion}

The viscosity of EPDM/SMR L blends adhesive decreases with increasing EPDM content. This observation is associated with the dilution effect of EPDM which has a lower viscosity compared to SMR L rubber. The decrease in tack with $\%$ EPDM is attributed to the decrease in wettability. Tack remains nearly at constant value after phase inversion at $40 \%$ EPDM content. For the three modes of peel tests, peel strength also decreases with EPDM content, an observation which is attributed to the decrease in wettability due to the non-rubbery behaviour of EPDM. However, for the shear strength, maximum value is observed at $20-40 \%$ EPDM. This finding is ascribed to the culmination of cohesive and adhesive strength at the optimum EPDM content. All the adhesion properties in this study are dependent on coating thickness. Higher coated sample exhibits higher adhesion values compared to that of lower coating thickness. This phenomenon is explained by the presence of higher amount of adhesive which enhances the viscoelastic response of the blend adhesive that is necessary for better adhesion. From this study, it can be concluded that the optimum blend ratio of EPDM/SMR L blend adhesive is $20 \% \mathrm{EPDM}$ where the shear and peel strengths indicate the best adhesion properties.

\section{Acknowledgment}

The authors acknowledge the Science Fund provided by Ministry of Science, Technology and Innovation (MOSTI), Malaysia for this study. There is no conflict of interests in the submitted paper.

\section{References}

[1] D. Satas, Ed., Handbook of Pressure Sensitive Adhesive Technology, Van Nostrand Reinhold, New York, NY, USA, 1982.

[2] Y. C. Leong, L. M. S. Lee, and S. N. Gan, "The viscoelastic properties of natural rubber pressure-sensitive adhesive using acrylic resin as a tackifier," Journal of Applied Polymer Science, vol. 88, no. 3, pp. 2118-2123, 2003.

[3] M. Fujita, M. Kajiyama, A. Takemura, H. Ono, H. Mizumachi, and S. Hayashi, "Effects of miscibility on peel strength of natural-rubber-based pressure-sensitive adhesives," Journal of Applied Polymer Science, vol. 70, no. 4, pp. 777-784, 1998.

[4] M. Fujita, A. Takemura, H. Ono, M. Kajiyama, S. Hayashi, and H. Mizumachi, "Effects of miscibility and viscoelasticity on shear creep resistance of natural-rubber-based pressuresensitive adhesives," Journal of Applied Polymer Science, vol. 75, no. 12, pp. 1535-1545, 2000.
[5] J. P. Phillips, X. Deng, R. R. Stephen et al., "Nano- and bulk-tack adhesive properties of stimuli-responsive, fullerenepolymer blends, containing polystyrene-block-polybutadieneblock-polystyrene and polystyrene-block-polyisoprene-blockpolystyrene rubber-based adhesives," Polymer, vol. 48, no. 23, pp. 6773-6781, 2007.

[6] J. P. Phillips, X. Deng, M. L. Todd et al., "Singlet oxygen generation and adhesive loss in stimuli-responsive, fullerenepolymer blends, containing polystyrene-block-polybutadieneblock- polystyrene and polystyrene-block-polyisoprene-blockpolystyrene rubber-based adhesives," Journal of Applied Polymer Science, vol. 109, no. 5, pp. 2895-2904, 2008.

[7] W. Smitthipong, M. Nardin, J. Schultz, and K. Suchiva, "Adhesion and self-adhesion of immiscible rubber blends," International Journal of Adhesion and Adhesives, vol. 29, no. 3, pp. 253258, 2009.

[8] M. M. Magida, Y. H. Gad, and H. H. El-Nahas, "The use of compatible blend of styrene-vinylacetate copolymer/natural rubber latex in pressure-sensitive adhesive applications by using irradiation and chemical initiation," Journal of Applied Polymer Science, vol. 114, no. 1, pp. 157-165, 2009.

[9] O. Stephen, R. Fatima, and A. A. Ikechukwu, "Adhesive formulations with ternary blends using simplex lattice design," International Journal of Physical Sciences, vol. 5, pp. 2098-2103, 2010.

[10] S. A. Da Silva, C. L. Marques, and N. S. M. Cardozo, "Composition and performance of Styrene-Isoprene-Styrene (SIS) and Styrene-Butadiene-Styrene (SBS) hot melt pressure sensitive adhesives," The Journal of Adhesion, vol. 88, pp. 187-199, 2012.

[11] S. A. Riyajan and N. Pheweaw, "Modification of skim rubber blended with poly (vinyl alcohol) to be applied as a biodegradable pressure-sensitive adhesive: effect of 2,6-di-tbutyl-4-methylphenol and hydrocarbon resin," Rubber Chemistry and Technology, vol. 85, no. 4, pp. 547-558, 2012.

[12] G. Gao, Z. Zhang, Y. Zheng, and Z. Jin, "Effect of magnesium methacrylate and zinc methacrylate on bond properties of thermal insulation material based on NBR/EPDM blends," Journal of Applied Polymer Science, vol. 113, no. 6, pp. 3901-3909, 2009.

[13] B. T. Poh and L. N. Ong, "Adhesion properties of styrenebutadiene rubber (SBR)/Standard Malaysian Rubber (SMR L)based adhesives in the presence of phenol formaldehyde resin," eXPRESS Polymer Letters, vol. 1, no. 10, pp. 654-659, 2007.

[14] B. T. Poh and S. S. Heng, "Effect of blend ratio on adhesion properties of pressure-sensitive adhesives prepared from SBR/SMR L blends," Polymer-Plastics Technology and Engineering, vol. 47, no. 3, pp. 325-329, 2008.

[15] B. T. Poh and A. L. Lim, "Adhesion properties of pressuresensitive adhesives prepared from SMR 10/ENR 25, SMR 10/ENR 50, and ENR 25/ENR 50 blends," Journal of Applied Polymer Science, vol. 109, no. 1, pp. 115-119, 2008.

[16] G. Gierenz and W. Karmann, Eds., Adhesives and Adhesive Tapes, Wiley-VCH, New York, NY, USA, 2001.

[17] F. W. Barlow, Rubber Compounding: Principles, Materials, and Techniques, Marcel Dekker, New York, NY, USA, 1988.

[18] B. T. Poh and C. L. Chee, "Effect of coumarone-indene resin on adhesion property of SMR 20-based pressure-sensitive adhesives," International Journal of Polymeric Materials and Polymeric Biomaterials, vol. 56, no. 3, pp. 247-255, 2007. 
[19] B. T. Poh and G. K. Khok, "Tensile property of epoxidized natural rubber/natural rubber blends," Polymer, vol. 39, no. 1, pp. 151-161, 2000.

[20] C. K. L. Davies, S. V. Wolfe, I. R. Gelling, and A. G. Thomas, "Strain crystallization in random copolymers produced by epoxidation of cis 1,4-polyisoprene," Polymer, vol. 24, no. 1, pp. 107-113, 1983. 

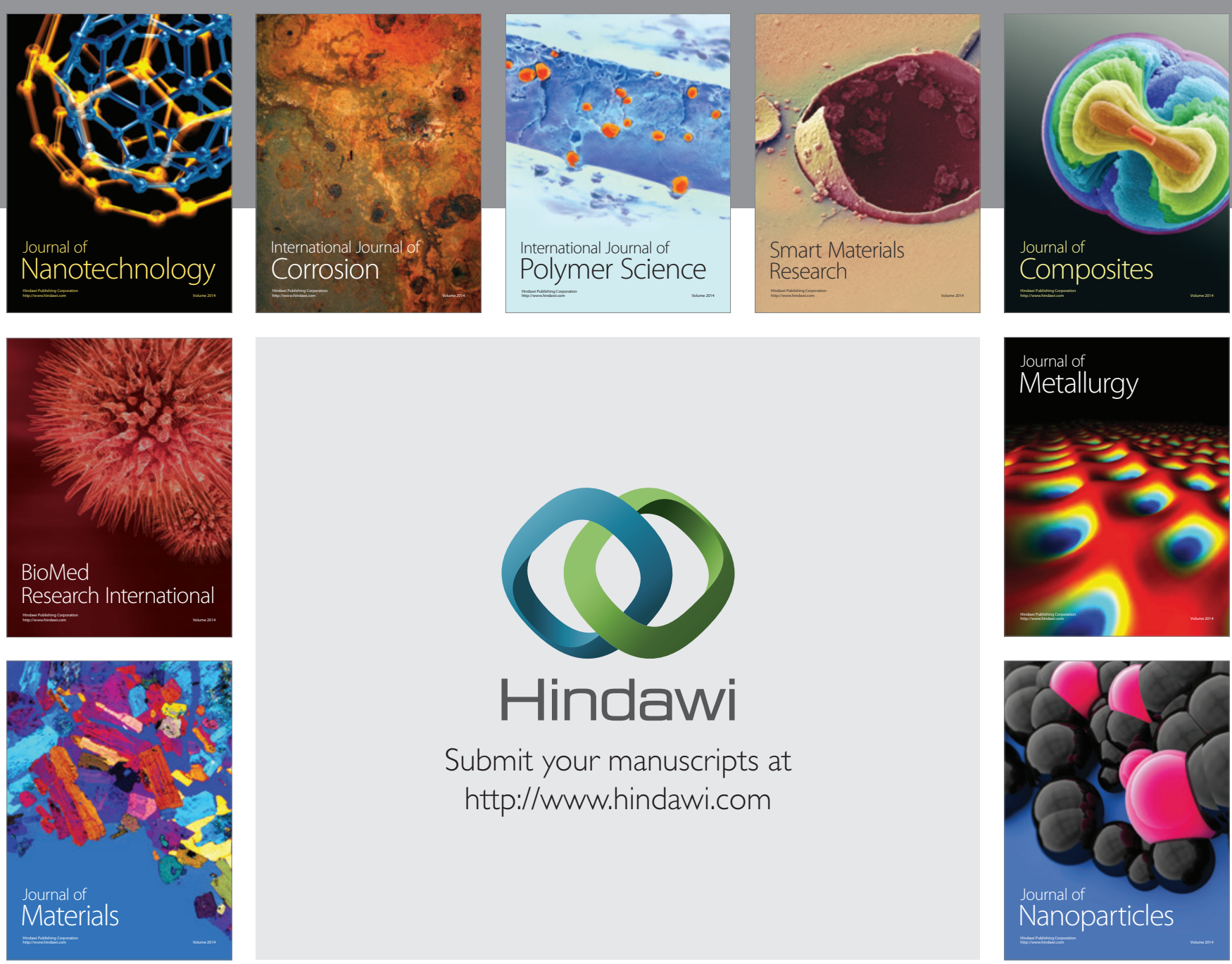

Submit your manuscripts at http://www.hindawi.com
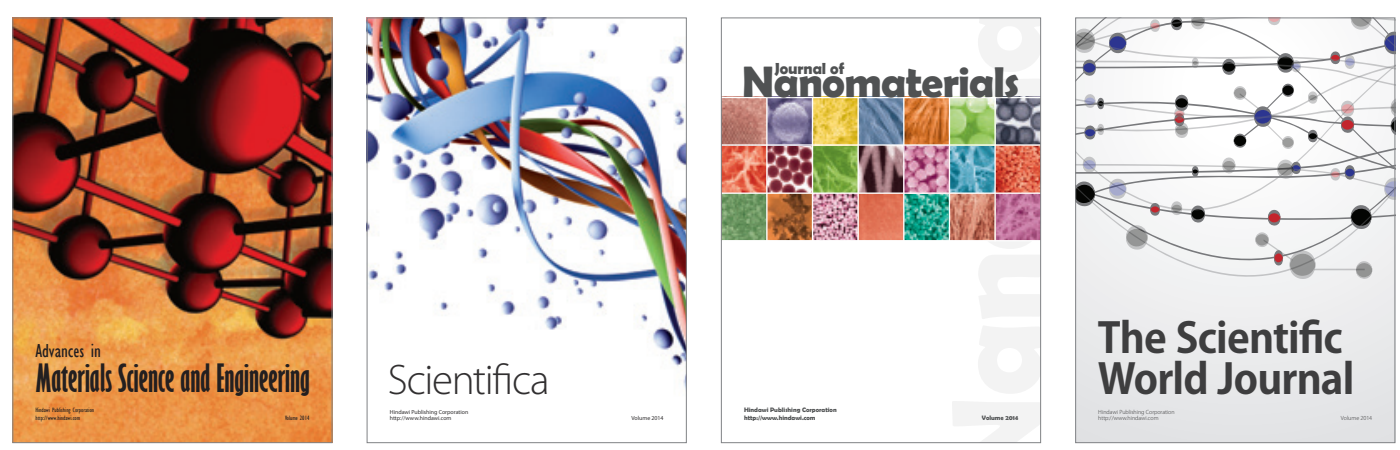

\section{The Scientific World Journal}
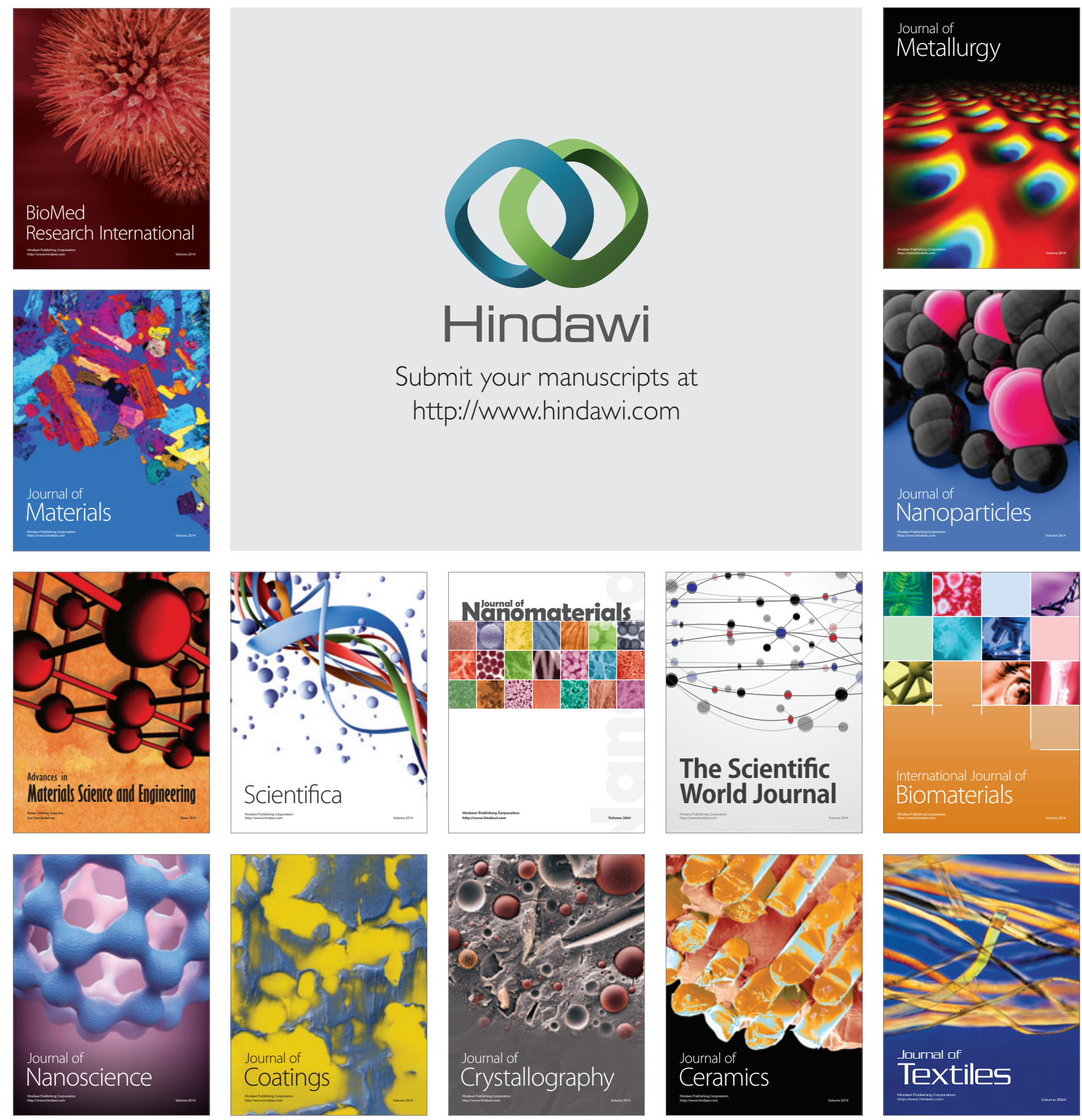